\title{
A LUDICIDADE NOS ESPAÇOS/TEMPOS ESCOLARES
}

\section{THE PLAYFULNESS IN THE SCHOOL SPACES \\ Kellen Cristina Alves BERNARDELLI ${ }^{1}$ Priscila Gervásio TEIXEIRA ${ }^{2}$}

\begin{abstract}
Resumo: $O$ presente artigo traz como enfoque principal a questão da ludicidade na sala de aula, abordada na Unidade 04 do caderno de formação do PACTO Nacional pela Alfabetização na Idade Certa. Pretende-se elucidar um olhar crítico-reflexivo sobre o material citado, abordando as aproximações e distanciamentos desse material com o cotidiano da sala de aula, buscando compreender a importância do lúdico no desenvolvimento infantil e seu rebatimento no processo educativo e na vida da criança. A metodologia utilizada foi a pesquisa bibliográfica do material do PACTO e a análise de autores clássicos e contemporâneos sobre o assunto. Portanto, 0 que se pretende, revelando a ludicidade na sala de aula e em outros espaços, é enfatizar a importância das atividades lúdicas como recurso pedagógico e como elemento para fruição infantil. O texto também faz apontamentos sobre a importância da formação lúdica do professor para a dimensão pessoal e profissional do docente.
\end{abstract}

Palavras-chave: Ludicidade, Alfabetização, Formação docente.

Abstract: This article focuses mainly on the issue of playfulness in the classroom, discussed in Unit 04 of the terms of the PACTO Nacional pela Alfabetização na Idade Certa. It is intended to elucidate a critical and reflexive view of the quoted material, addressing the similarities and differences from this material from the everyday classroom, seeking to understand the importance of playfulness in children's development, in their educational process and life. The methodology used was the literature of material from PACTO and the analysis of classic and contemporary authors on the subject. So, what is intended, enlightening the playfulness in the classroom and in other areas, is to exploit recreational activities as an educational resource and as a child element of achievement. The text also makes

1 Mestre em Educação pela Universidade Federal de Uberlândia, docente da Alfabetização Inicial no Colégio de Aplicação (CApEseba/UFU) da Universidade Federal de Uberlândia.

2 Especialista em Educação pela Universidade Federal de Uberlândia, docente da Alfabetização Inicial do Colégio de Aplicação (CApEseba/UFU) da Universidade Federal de Uberlândia. 
notes about the importance of playful teacher training for personal and professional dimensions of teaching.

Keywords: Playfulness, Literacy, Teacher training.

\section{Introdução}

O presente artigo traz como enfoque principal a questão da ludicidade na sala de aula, abordada na Unidade 04 do caderno de formação do PACTO Nacional pela Alfabetização na Idade Certa ${ }^{3}$.

O texto pretende elucidar um olhar crítico-reflexivo sobre o material citado, abordando as aproximações e distanciamentos desse material com o cotidiano da sala de aula, buscando compreender a importância do lúdico no desenvolvimento infantil e seu rebatimento no processo educativo e na vida da criança. A metodologia utilizada foi à pesquisa bibliográfica do material do PACTO e a análise de autores clássicos e contemporâneos sobre a temática.

Enfim, o que se pretende ao se revelar a ludicidade na sala de aula é explorar o jogo e as brincadeiras nos

${ }^{3}$ A palavra PACTO, em maiúscula, será utilizada ao longo do texto para referir-se ao Pacto Nacional pela Alfabetização na Idade Certa, por se tratar de uma convenção acordada entre o MEC e as entidades federativas do Brasil que atendem as crianças no ciclo de alfabetização. 
momentos oportunos, considerando os aspectos de desenvolvimento de cada faixa etária, relacionando com as diversas áreas do conhecimento, enfatizando as atividades lúdicas como recurso pedagógico e como elementos para fruição infantil. O texto também faz apontamentos sobre a importância da formação lúdica do professor para a dimensão pessoal e profissional do docente.

\subsection{Lúdico e a Formação Lúdica do Professor}

Em busca do conceito da palavra lúdico, encontramos sua origem no latim ludus, cujo significado é associado à brincadeira, ao jogo, ao divertimento. Para Friedmann (1992), estudiosa desse campo, a atividade lúdica compreende os conceitos de brincadeira, jogo e brinquedo.

Brincadeira refere-se, basicamente, à ação de brincar, ao comportamento espontâneo que resulta de uma atividade não-estruturada; jogo é compreendido como uma brincadeira que envolve regras; brinquedo é utilizado para designar o sentido de objeto de brincar; atividade lúdica abrange, de forma mais ampla, os conceitos anteriores (FRIEDMANN, 1992 p.12). 
Ao pesquisarmos outros autores, como Huizinga (2007) e Kishimoto (2008), percebemos que existem aproximações e distanciamentos em relação ao termo "lúdico". Kishimoto (2008) não concorda que a palavra Iúdico seja utilizada como sinônimo de jogo, brinquedo e brincadeira, como Friedmann (1992) defende.

Para esses autores a ludicidade é como base para aprendizagem. Na busca de aprofundarmos nesse assunto, deparamo-nos com a pesquisa de Carleto (2003), a qual cita estudiosos defensores do lúdico há mais de dois séculos:

Rousseau, Pestalozzi, Froebel, Dewey, Claparède, Montessori, Piaget e Vygotsky foram importantes na organização de concepções pedagógicas em que a atividade lúdica é percebida como um processo pelo qual a criança enriquece o senso de responsabilidade, desenvolve a autoexpressão e desenvolve-se física, cognitiva e socialmente (CARLETO, 2003, p.98).

Considerando essas áreas de desenvolvimento como benefício físico, o lúdico favorece o crescimento da criança, o desenvolvimento das habilidades motoras e de expressão 
corporal. Em relação ao desenvolvimento cognitivo, o brincar contribui para a desinibição, estimula as ações intelectuais, desenvolve habilidades perceptuais, como atenção e consequentemente a memória. As contribuições sociais são percebidas quando a criança simboliza uma realidade que ainda não pode alcançar e aprende a interagir com outras pessoas, compartilhando, relacionando-se. As atividades lúdicas possibilitam que as crianças reelaborem criativamente sentimentos e conhecimentos e edifiquem novas possibilidades de interpretação e de representação do real.

Com base no material analisado, Brasil (2012a), outra contribuição do brincar está no âmbito escolar, pois

do ponto de vista didático, as brincadeiras promovem situações em que as crianças aprendem conceitos, atitudes e desenvolvem habilidades diversas, integrando aspectos cognitivos, sociais e físicos. Podem motivar as crianças para se envolverem nas atividades e despertam 0 interesse pelos conteúdos curriculares (p. 07).

Quanto aos conteúdos curriculares, podemos verificar no material a ideia de que a realização de brincadeiras e 
jogos com os materiais do acervo escolar, inclusive com os materiais enviados pelo Ministério da Educação (MEC), não significa privilegiar a apropriação exclusiva do Sistema de Escrita Alfabético (SEA), mas a realização das atividades lúdicas auxiliam na aprendizagem dos conteúdos de outros componentes curriculares, a saber: Matemática, Língua Portuguesa, Ciências, História, Geografia, Arte, dentre outros. O lúdico é, assim, percebido como um recurso facilitador e motivador da aprendizagem escolar (KISHIMOTO, 2008).

Nesse sentido, o lúdico propicia ações tanto voltadas para a aprendizagem como para a vida da criança propriamente dita, caracterizando-se como elemento inclusivo na dimensão individual e coletiva desse sujeito. Assim, a ludicidade é abordada no material do PACTO como recurso facilitador para uma educação inclusiva. Sendo que a educação inclusiva é tema transversal em todo o material produzido pelo PACTO Nacional pela Alfabetização na Idade Certa em 2012. 
Tendo em vista a inclusão das crianças, o professor recorrerá às atividades avaliativas para reconhecer e planejar as melhores estratégias didáticas, visto que "qualquer criança necessita ser cuidada e pode apresentar dificuldades de aprendizagem em alguma fase da vida ou em relação a algum conteúdo específico" (BRASIL, 2012a, p. 8). E continua: "É nesse sentido que ressaltamos a dimensão cuidadora da ação docente. O professor precisa avaliar e ensinar, cuidando de cada criança, estando atento às suas necessidades e a seus avanços" (p. 8).

Mediante tarefa nada fácil, observamos que garantir a todos o direito ao brincar auxilia todo o trabalho pedagógico. Dentro desse contexto, existe outro elemento que não pode ficar de fora: o próprio professor. Para tanto, buscamos compreender também a importância da formação lúdica na formação do professor. Exigir dele práticas lúdicas demanda reconhecer seus saberes.

Consultamos Andrade (2008), cuja discussão trata da formação lúdica do professor em seus escritos. Ela cita que quando o professor inicia um trabalho com propostas 
lúdicas, ele também deve brincar. O lúdico é o espaço de estar "com": com as crianças e também com os adultos. Não seria possível pensar as brincadeiras para as crianças sem considerá-las como uma oportunidade também para o educador participar.

A autora ainda afirma que a maior parte dos cursos de formação não contempla esse aspecto, pois não considera que a experiência cultural do adulto possa favorecer sua imaginação. Além dos fatos apresentados, outra justificativa para a inserção do lúdico nos cursos de formação é a importância de ampliar o repertório de brinquedos e brincadeiras na vida do professor.

Para a autora, "o brincar" não tem poderes mágicos. Precisamos nos lembrar de que crianças aprendem 0 mundo menos pelos seus brinquedos e jogos e mais pelas relações humanas que as cercam: uma proposta instigante de um professor pode ser mais interessante para as crianças do que uma brincadeira.

Em relação às contribuições do lúdico para os aspectos sociais, o material do PACTO cita benefícios para as 
crianças, já Andrade (p. 62, 2008) estende para o universo dos adultos: "A busca por situações favorecedoras de integração entre as crianças, sabendo da sua riqueza para o desenvolvimento humano deve se estender para as relações docentes, visto que o trabalho docente tem se demonstrado tão individualizado".

Nessa perspectiva, a fim de levarmos os educadores a uma reflexão sobre sua práxis pedagógica, recorremos a Freire (1996). Em seu texto clássico do livro "Pedagogia da Autonomia", esse autor nos adverte para o fato de que: "Ensinar exige a corporeificação das palavras pelo exemplo". Freire preconizava o que Andrade (2008) cita a seguir, a respeito de sermos brincantes para propormos brincadeiras:

As transformações mais interessantes e significativas que observamos nas práticas lúdicas junto aos alunos decorrem de uma formação que favorece a emersão da ludicidade/humanidade do professor e possibilita que ele a incorpore e a esparrame para além de brinquedos e brincadeiras. Viver a interação ser/fazer é essencial para todos nós, artesãos do educar. Quando não oferecemos ao professor a oportunidade da experiência lúdica, negamos-lhe toda a riqueza 
que pretendemos que ele ofereça aos seus alunos. Há muito tempo estamos defendendo a autonomia das crianças. Mas, quantas vezes, esta mesma autonomia falta ao professor? Será que estamos vivendo, com o lúdico, igual contradição? (ANDRADE, 2008, p. 58).

Ainda para Andrade (2008), o acervo de brinquedos e jogos é importante por tudo o que pode oferecer, mas quando ele ganha exagerada importância em si mesmo, instala-se uma preocupação também exagerada de cuidados, que inviabiliza seu uso. Não se constrói um espaço lúdico apenas com uma sala de jogos e brinquedos, a qual não existe sem adultos e crianças envolvidos em uma proposta. São as pessoas que ressignificam esse espaço.

Outra crítica que salientamos é quanto à didatização 4 da ludicidade. Em todo o material analisado, Unidade 4 do PACTO (BRASIL, 2012a, 2012b, 2012c), o lúdico é visto como recurso pedagógico e não se comenta quanto ao

4 Entende-se por didatização práticas pedagógicas que visam transformar um conhecimento do campo do saber para o campo do ensino. 
"Brincar" - como ato de descoberta, de investigação, de criação.

No sentido da didatização do lúdico, Debortoli (2005) relata em sua pesquisa que o discurso do brincar tem feito surgir, especialmente na Educação Infantil, um ideário pedagógico que faz da brincadeira um de seus conteúdos, de seus meios e, muitas vezes, uma finalidade.

Por outro lado, a pesquisadora

observou e analisou as mediações de professoras e percebeu a dificuldade delas em reconhecer seu lugar social e a importância de mediações sistemáticas, de projetos e princípios claros e intencionais. As ações observadas reforçavam a ideia de aprendizagem natural e espontânea (DEBORTOLI, 2005, p. 5).

Assim, compreendemos o lúdico também como espaço de aprendizagem, que não necessita ter objetivos pedagógicos específicos no ato de brincar, jogar etc., a todo momento.

Após discorrermos sobre o lúdico e a formação lúdica do professor, optamos por aprofundar o tema "Brincar" em um capítulo específico, na tentativa de tecer contribuições mais aprofundadas sobre o assunto. 


\section{0 brincar}

O brincar é uma ação eminentemente lúdica. A brincadeira pode e deve fazer parte de toda nossa vida, mas é reservada em nossa sociedade para a infância.

Para Corsino (2008), a noção de infância não é uma categoria natural, mas sim histórica e cultural. A diferenciação entre crianças e adultos vai depender do contexto e das condições sócio-históricas e culturais em que vivem.

Numa perspectiva histórica sobre a infância na Europa, os estudos de Philippe Ariès (1986), no seu livro História Social da Criança e da Família, revelaram que a ideia de infância, no sentido de diferenciação do adulto, é uma construção da modernidade, começando a surgir nos finais do século XVII, nas camadas superiores da sociedade, e se sedimentando no século XVIII (CORSINO, 2008, p. 14).

A infância atual é, portanto, fruto da modernidade com suas evoluções e considerações culturais. Por conseguinte, os modos de brincar também. Nesse sentido, ao consultarmos o livro Ensino Fundamental de nove anos: orientações para a inclusão da criança de seis anos de idade, encontramos o texto de Borba (2006) e constatamos 
que as crianças reproduzem e recriam, encarnam possibilidades de mudanças e de renovação da experiência humana. Elas incorporam as experiências sociais e culturais do brincar por meio das relações que estabelecem com os outros. No entanto, valorizar a brincadeira não é apenas permiti-la, mas também promovê-la (BORBA, 2006).

As teorias que abordam o tema não conseguiram convencer que as práticas das brincadeiras são espaços de aprendizagens e que o plano informal das brincadeiras colabora com o plano formal da aprendizagem.

Alguns adultos cantam, falam de sua própria infância, observam as crianças brincando, leem, contam histórias e ensinam brincadeiras. Outros pensam que as crianças não entendem nada e que só é preciso cuidar para que não fiquem doentes, não passem fome, frio ou sede. Quando estão brincando, preocupam-se apenas em evitar que se machuquem ou briguem entre si (PORTO, 2008, p. 4).

Para os estudos da psicologia, o brincar é uma atividade humana criadora, na qual a imaginação, a fantasia e a realidade interagem na produção de novas possibilidades de interpretação, de expressão e de ação pelas crianças. 
A brincadeira, para Vygotsky (1998), cria uma zona de desenvolvimento proximal, permitindo que as ações da criança ultrapassem o desenvolvimento já alcançado. A brincadeira é uma prática cultural, fruto das ações humanas transmitidas de modo inter e intrageracional, e como forma de ação cria e transforma significados sobre o mundo. Por meio da brincadeira, as crianças planejam, negociam, discutem para brincar.

A brincadeira requer específica comunicação. É um trabalho nobre no campo das linguagens: discurso organizado com lógicas e características próprias. Ela também tem uma função humanizadora, pois promove liberdade, espontaneidade e sociabilidade (BRASIL, 2012a).

Os professores devem observar as crianças brincando e brincar com elas, como citamos na seção anterior. 0 lúdico não deve se resumir às propostas pedagógicas de pretexto ou instrumento para o ensino de conteúdos. Para que uma proposta pedagógica seja lúdica é importante que permita a fruição, a decisão, a escolha, as descobertas, as 
perguntas e soluções por parte das crianças/adolescentes (ANDRADE, 2008).

Borba (2006) levanta uma questão que transita no ambiente docente: brincar é importante, mas como planejar as atividades que giram em torno dessa ação? A autora se propõe a responder com algumas sugestões: organizando rotinas; criando espaços de jogos e brincadeiras e compartilhando-os; colocando-se à disposição das crianças; observando as crianças nas brincadeiras para melhor conhecê-las; percebendo as alianças, amizades; estabelecendo pontes e centrando a ação pedagógica no diálogo.

Na Escola de Educação Básica (ESEBA), da Universidade Federal de Uberlândia, elegemos três espaços/tempos para essas observações: a sala de aula, o pátio e a brinquedoteca. A escolha por esta instituição se justifica por nela trabalharmos e esses espaços são os que mais nos possibilitam observar as crianças em interação dentro do nosso fazer pedagógico cotidianamente. A ESEBA é o colégio de aplicação da Universidade Federal de 
Uberlândia e atende crianças a partir de 4 anos na Educação Infantil e em todo Ensino Fundamental. Ela está situada em Uberlândia - Minas Gerais

Abordaremos esses três espaços/tempos no próximo tópico.

\section{A ludicidade nos espaços escolares: a ESEBA em foco}

Os espaços escolares são propícios aos prazeres e descontentamentos que envolvem o processo ensinoaprendizagem. Elegemos os espaços: sala de aula, pátio e brinquedoteca da Eseba como espaços/tempos lúdicos por levar em conta nossas experiências docentes na instituição.

O presente texto não é resultado de pesquisa, mas sim de observações, aliadas à análise do material do PACTO e a outras referências que procuram evidenciar o que os autores revelam sobre a ludicidade e quais dessas evidências encontramos na instituição citada, ou seja, o que os espaços analisados na Eseba reproduzem de acordo com os teóricos apresentados. 
Quando consideramos que é no ciclo da alfabetização que se consolida e se aprofunda ${ }^{5}$ o trabalho com a apropriação do Sistema de Escrita Alfabética (SEA), com a leitura e com a produção de textos, de modo integrado às aprendizagens relativas aos diferentes componentes curriculares (BRASIL, 2012b), a sala de aula se torna o lugar de excelência para essas ações, mesmo considerando todos os espaços escolares como educativos.

Contudo, "a preocupação com os conteúdos e com as metodologias pode levar ao esquecimento de que os alunos precisam de alguns estímulos para que se envolvam mais efetivamente com o que a escola selecionou para eles e, assim, se desenvolvam intelectualmente" (BRASIL, 2012b, p. 6). Dessa forma, é importante promover atividades estimulantes e desafiadoras a fim de que se atinjam os objetivos pretendidos com o que se pretende ensinar.

Na tentativa de tornar mais agradável o processo de apropriação do SEA, as atuais perspectivas de ensino-

${ }^{5}$ Introduzir, aprofundar e consolidar são ações que os direitos de aprendizagens trazem no documento analisado. $O$ Ciclo de Alfabetização no Pacto e na Eseba compreendem os mesmos anos de ensino: $1^{\circ}, 2^{\circ}$ e $3^{\circ}$ anos do Ensino Fundamental. 
aprendizagem de diferentes áreas do conhecimento passaram a utilizar as atividades lúdicas, os jogos, os brinquedos e as brincadeiras como recursos pedagógicos importantes na relação ensino- aprendizagem.

A Eseba dispõe de um rico acervo de materiais pedagógicos, jogos e livros, assim como grande parte das escolas no país, sejam das redes municipais, estaduais e federais de ensino, principalmente as inseridas no PDEEscola $^{6}$, as quais receberam e recebem a maioria desse acervo, por meio dessa política pública. Além da formação de professores, outro importante eixo do PACTO é o estímulo do uso desses materiais, que por vezes ficavam trancados em salas nas escolas, sem que os professores tivessem acesso (BRASIL, 2012a).

Na sala de aula, o trabalho com atividades lúdicas está cada vez mais frequente nessa instituição, o qual é associado também ao conteúdo. Os docentes elaboram

${ }^{6}$ PDE Escola - Plano de Desenvolvimento da Escola é um programa de apoio à gestão escolar baseado no planejamento participativo e seu objetivo é auxiliar as escolas públicas a melhorar a sua gestão. Para as escolas priorizadas pelo programa, o MEC repassa recursos financeiros destinados a apoiar a execução de todo ou parte do seu planejamento. Fonte: http://pdeescola.mec.gov.br/ acesso em $16 / 07 / 2014$. 
jogos, histórias para apresentar ou complementar o currículo para os alunos. Os jogos, em especial, criam condições fundamentais para o desenvolvimento do aluno, além de promover a participação coletiva e individual em ações que possam melhorar o seu desenvolvimento cognitivo, afetivo e social.

Portanto, as atividades lúdicas nas salas de aulas da Eseba são utilizadas como recursos pedagógicos para auxiliar o processo de ensino-aprendizagem.

O segundo espaço citado como lúdico é a brinquedoteca. Espaço porque existe uma infraestrutura destinada a esse uso e tempo porque é previsto na grade curricular da escola. Precisaríamos de mais tempo para nos debruçar sobre as funções e atuações da brinquedoteca: seus personagens, seus recursos; o que daria um estudo à parte, como fez Brougere e Roucous (2003), Silva e Resende (2010), dentre outros.

Pesquisadores franceses chamam a atenção para o fato de que a atuação do educador nas brinquedotecas é sutil e muitas vezes pouco visível, o que contribui para uma 
certa insegurança quanto a sua importância. Notamos que na instituição em análise existe uma proposta pedagógica para a brinquedoteca que Ihe dá identidade.

Uma brinquedoteca é colocada em funcionamento por um profissional em função de um conceito geral que prescreve alguns aspectos de identidade e atendimento, mas também em função das concepções pessoais sobre, por exemplo, o que é brincadeira, criança e educação (Brougere e Roucous, 2003, p. 52).

$\mathrm{Na}$ pesquisa sobre atuações dos profissionais de brinquedoteca realizada por Porto (2008), nos deparamos com as seguintes considerações:

1) A atuação não se define apenas pela ação de favorecer a brincadeira com os brinquedos, mas por uma representação particular do lúdico que sustenta todas as práticas e que remete à gratuidade e à liberdade próprias do ato de brincar; 2) As pessoas que trabalham nesses locais devem ser capazes de aconselhar, apresentar, explicar e mediar a participação nos jogos e brincadeiras; 3) A atuação se caracteriza e se particulariza também por uma presença e por uma forma de se relacionar dinâmica e aberta, que tem como objetivo o desenvolvimento da atividade lúdica e, mais amplamente, o acolhimento da autonomia e da liberdade num contexto organizado e seguro (PORTO, 2008, p.6). 
Notamos que o trabalho realizado na brinquedoteca é tão significante que as crianças a elegem como um dos melhores espaços da escola.

Mediante o exposto, é nesse espaço da Eseba, como citaram Silva e Resende (2010, p. 75), que "reconhecemos a validade do tempo e do espaço para brincar na vida das crianças, considerando-as como produtoras e fruidoras de cultura". Validamos a afirmação das autoras de que a brinquedoteca da Eseba também é espaço de produção e fruição de cultura e não como mais um recurso pedagógico.

Por último, citamos o pátio como o espaço lúdico da escola também visto na mesma perspectiva da brinquedoteca - crianças usuárias como produtoras e fruidoras de cultura. A diferença é que no pátio da instituição não existe mediação docente, como na sala de aula e na brinquedoteca, apesar de existir uma regulamentação quanto ao recreio orientado, mas o pátio, como dissemos, é dedicado a brincadeiras livres.

Ao pesquisar sobre o assunto, não encontramos na literatura referências sobre o pátio da escola como espaço 
para o brincar, somente enquanto elemento de socialização (EMELL, 1996).

Faz parte da cultura escolar da Eseba a existência do pátio para as crianças da Educação Infantil e Alfabetização Inicial (turno vespertino). Elas encontram e são encontradas pelos colegas da mesma turma e de outras turmas formando um grande público infantil. São crianças dispostas às atividades lúdicas criadas por elas mesmas e/ou são reprodutoras de brinquedos, brincadeiras e jogos transmitidos historicamente, evidenciando aspectos culturais.

\section{Considerações finais}

O que o material do PACTO defende "é que a escola seja inclusiva e centrada no prazer de aprender" (BRASIL, 2012a, p. 11). Nesse sentido, os jogos e as brincadeiras são vistos como oportunidade de mediação entre o prazer e o conhecimento historicamente construído. Assim, a ludicidade e a aprendizagem são vistas como ações 
complementares, nas quais o lúdico se faz como recurso facilitador e motivador da aprendizagem escolar.

Os cursos de formação e as literaturas acadêmicas têm estimulado a utilização de jogos, brincadeiras e materiais pedagógicos, como recursos pedagógicos para o ensino-aprendizagem mais significativo, mas não devemos nos esquecer de que esses elementos - a brincadeira, 0 brinquedo, o jogo, os materiais pedagógicos, os livros de literatura - carregam um saber em potencial que necessita muitas vezes da mediação do professor.

Portanto, o docente desempenha papel fundamental mediando as situações que envolvem os elementos citados para a sistematização dos conhecimentos. A forma como trabalhará é que denotará a ampliação da linguagem, de seus conhecimentos e o desenvolvimento cognitivo sóciorelacional da criança. É nesse processo que ocorre a aprendizagem, que se dá por construção do sujeito na interação com o outro e com o conhecimento (KISHIMOTO, 2008). 
Como se pode observar, construímos, ao longo deste texto, três categorias importantes para se pensar os espaços/tempos na escola, uma para cada espaço citado na escola: atividades lúdicas na sala de aula como recurso pedagógico; atividades lúdicas na brinquedoteca e atividades lúdicas livres no pátio como fruição de culturaำ

Assim, o material do PACTO analisado contribui para a formação do professorado do Ciclo de Alfabetização no que tange à utilização do lúdico como recurso pedagógico numa perspectiva de educação inclusiva, mas apresenta lacunas, para as quais buscamos respostas, as quais são: a importância do lúdico para deleite e fruição no desenvolvimento infantil e na formação lúdica do professor.

\section{Bibliografia}

ANDRADE, Cyrce. A Formação Lúdica do Professor. In: Jogos e brincadeiras: desafios e descobertas. 2.ed. Salto para o Futuro. Ano XVIII boletim 07 - Maio de 2008.

ARIÈS, Philippe. História social da criança e da família. 2. ed. Rio de Janeiro: Guanabara, 1986.

${ }^{7}$ Entende-se fruição de cultura como termo empregado para destacar uma ação que leva ao desenvolvimento cognitivo-afetivo e social. 
BORBA, Ângela Meyer. O brincar como um modo de ser e estar no mundo. In: Ensino fundamental de nove anos: orientações para a inclusão da criança de seis anos de idade - Brasília: FNDE, Estação Gráfica, 2006.

BRASIL. Pacto nacional pela alfabetização na idade certa: ludicidade na sala de aula. Ano: 01, unidade 04. Ministério da Educação, Secretaria de Educação Básica, Diretoria de Apoio à Gestão Educacional Brasília: MEC, SEB, 2012a.

- Pacto nacional pela alfabetização na idade certa: vamos brincar de construir as nossas e outras histórias. Ano 02, unidade 04. Ministério da Educação, Secretaria de Educação Básica, Diretoria de Apoio à Gestão Educacional. Brasília: MEC, SEB, 2012b.

\section{- Pacto nacional pela alfabetização na idade}

certa: vamos brincar de reinventar histórias. Ano 03, unidade 04. Ministério da Educação, Secretaria de Educação Básica, Diretoria de Apoio à Gestão Educacional. Brasília: MEC, SEB, 2012c.

BROUGERE, G. e ROUCOUS, N. (org.) Le metier de ludothécaire: rapport d'une recherche realisee par etudiants du DEES en sciences du jeu: Universite Paris 13, sous la direction de Brougere e Roucous, em partenariat avec I'Association des Ludotheques Francaises, septembre, 2003.

CARLETO, Eliana Aparecida. O lúdico como estratégia de aprendizagem. Revista Olhares e Trilhas. Uberlândia, v. 4, n.4, 2003, p. $97-104$.

CORSINO, Patrícia. Pensando a infância e o direito de brincar. In: Jogos e brincadeiras: desafios e descobertas. 
2. ed. Salto para o Futuro. Ano XVIII. Boletim 07 - Maio de 2008.

DEBORTOLI, J. A. Educação Infantil e conhecimento escolar. In: Carvalho, A. - et al. (orgs.) Brincar(es). Belo Horizonte: Ed. UFMG. Pró-Reitoria de Extensão/UFMG, 2005.

EMMEL, Maria Luísa. O pátio da escola: espaço de socialização. Revista Paidéia, no 10-11. Ribeirão Preto, 1996. Disponível em $<$ http://www.scielo.br/scielo.php?pid=S0103-

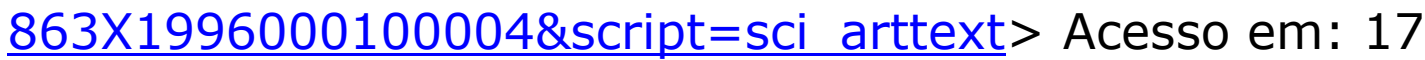
jul. 2014.

FREIRE, Paulo. Pedagogia da Autonomia: saberes necessários à prática educativa. São Paulo: Paz e Terra, 1996.

FRIEDMANN, Adriana. 0 Direito de Brincar: a brinquedoteca. São Paulo: Scritta: ABRINQ, 1992.

KISHIMOTO, Tizuko Morchida. (Org.). Jogo, brinquedo, brincadeira e a educação. 11 . ed. São Paulo: Cortez, 2008.

PDE-Escola. Plano de Desenvolvimento da Escola. Disponível em <http://pdeescola.mec.gov.br/> Acesso em: 16 jul. 2014.

PORTO, Cristina Laclette. Proposta Pedagógica. In: Jogos e brincadeiras: desafios e descobertas. 2. ed. Salto para o Futuro. Ano XVIII boletim 07 - Maio de 2008.

SILVA, Eliana Freitas Coelho; RESENDE, Keila de Fátima. Brinquedoteca: Um espaço do faz de conta infantil. Revista Olhares e Trilhas. Uberlândia, Ano XI, n.11, p. 65-76, 2010. 
